\title{
Reversal with sugammadex for rocuronium-induced deep neuromuscular block after pretreatment of magnesium sulfate in rabbits
}

\author{
Woon Seok Kang ${ }^{1}$, Kyo Sang Kim², and Shin Mi Song ${ }^{2}$ \\ Department of Anesthesiology and Pain Medicine, ${ }^{1}$ Konkuk University Medical Center, Konkuk University School \\ of Medicine, ${ }^{2}$ Hanyang University College of Medicine, Seoul, Korea
}

Background: Magnesium sulfate $\left(\mathrm{MgSO}_{4}\right)$ has been used in the treatment of pre-eclampsia, hypertension and arrhythmia. Magnesium enhances the neuromuscular block of rocuronium. This study has been conducted to evaluate the reversal efficacy of sugammadex from deep rocuronium-induced neuromuscular block (NMB) during consistent pretreatment of $\mathrm{MgSO}_{4}$ in rabbits.

Methods: Twenty-eight rabbits were randomly assigned to four groups, a control group or study groups (50\% $\mathrm{MgSO}_{4}$ $150-200 \mathrm{mg} / \mathrm{kg}$ and $25 \mathrm{mg} / \mathrm{kg} / \mathrm{h} \mathrm{IV}$ ), and received rocuronium $0.6 \mathrm{mg} / \mathrm{kg}$. When post-tetanic count 1-2 appeared, sugammadex 2, 4, and $8 \mathrm{mg} / \mathrm{kg}$ was administered in the 2-mg group, control and 4-mg group, and 8-mg group, respectively. The recovery course after reversal of sugammadex administration was evaluated in each group.

Results: The mean serum concentration of magnesium was maintained at more than $2 \mathrm{mmol} / \mathrm{L}$ in the study groups, and the total dose of $\mathrm{MgSO}_{4}$ was more than $590 \mathrm{mg}$. The reversal effect of sugammadex on rocuronium-induced NMB in pretreated $\mathrm{MgSO}_{4}$ was not different from that in the group without $\mathrm{MgSO}_{4}$. The recovery time to train-of-four ratio 0.9 after sugammadex administration in the 2 -mg group was longer than in the other groups $(\mathrm{P}<0.001)$; there were no other significant differences among the groups.

Conclusions: The reversal of sugammadex from a deep rocuronium-induced $\mathrm{NMB}$ during large pretreatment of $\mathrm{MgSO}_{4}$ was not affected. However, we should consider that the reversal effect of sugammadex varied depending on the dose.

Key Words: Magnesium sulfate, Pharmacodynamics, Rabbits, Rocuronium, Sugammadex.

Corresponding author: Kyo Sang Kim, M.D., Ph.D.

Department of Anesthesiology and Pain Medicine, Hanyang University College of Medicine, 222, Wangsimni-ro, Seongdong-gu, Seoul 04763, Korea

Tel: 82-2-2290-8680, Fax: 82-2-2299-8692

Email: kimks@hanyang.ac.kr

ORCID: http://orcid.org/0000-0002-2186-3484

Received: January 6, 2017.

Revised: February 15, 2017.

Accepted: February 17, 2017.

Korean J Anesthesiol 2017 April 70(2): 203-208

https://doi.org/10.4097/kjae.2017.70.2.203

\section{Introduction}

Eclampsia is most common complication of pregnancy with hypertension and proteinuria, with an incidence of 6-8\% [1]. Magnesium sulfate $\left(\mathrm{MgSO}_{4}\right)$ is used widely for the treatment and prevention of seizures in patients with eclampsia [2]. In the clinical field, to treat eclampsia, $\mathrm{MgSO}_{4}$ is initially bolus injected as a loading dose with $4 \mathrm{~g}$ and $2 \mathrm{~g} / \mathrm{h}$ is infused as maintenance dose, such that the serum concentration of magnesium reaches $2.0-3.5 \mathrm{mmol} / \mathrm{L}$. $\mathrm{MgSO}_{4}$ enhances the effects of muscle relaxation on non-depolarizing neuromuscular blocking agents

(c) This is an open-access article distributed under the terms of the Creative Commons Attribution Non-Commercial License (http://creativecommons.org/ licenses/by-nc/4.0/), which permits unrestricted non-commercial use, distribution, and reproduction in any medium, provided the original work is properly cited. 
(NMBA) by depressing the acetylcholine release at the motor end plate within neuromuscular junction, decreasing the excitability of muscular fibers, and decreasing the electric potential amplitude at the end plate [3].

Sugammadex, a modified $\gamma$-cyclodextrin, is a selective relaxant-binding agent. Sugammadex achieves rapid reversal of muscle relaxation by forming a tight complex with unbound steroidal NMBA molecules, such as rocuronium or vecuronium. A deep neuromuscular block (NMB) by rocuronium (1-2 posttetanic counts [PTC]) is reversed with $4.0 \mathrm{mg} / \mathrm{kg}$ of sugammadex [4]. A deep NMB has various advantages. It can provide a better surgical field with lower intra-abdominal pressure than a moderate NMB (1-2 train of four [TOF] counts), decrease postoperative pain and induce rapid recovery of bowel function [5]. It also improves the surgical view in microsurgery [6]. Czarnetzki et al. [7] reported that there was no effect of $\mathrm{MgSO}_{4}$ pretreatment on the sugammadex reversal for a deep NMB with rocuronium. However, this study was performed with one bolus injection of $60 \mathrm{mg} / \mathrm{kg} \mathrm{MgSO}_{4}$ and the serum magnesium concentration was $1.5 \mathrm{mmol} / \mathrm{L}$; this concentration was lower than the clinical concentration of $2.0-3.5 \mathrm{mmol} / \mathrm{L}$ for eclampsia treatment. In addition, there were various limitations for the maintenance of constant serum concentrations of magnesium.

The aim of this study was to evaluate the effect of high serum magnesium concentration on the sugammadex reversal of a rocuronium-induced deep NMB in experimental animals.

\section{Materials and Methods}

After approval by our institutional animal care and use committee (CLAS MRCC HYU 2014-0069), we used 28 adult male New Zealand white rabbits, weighing 3.3-3.8 kg (3.5 $\pm 0.2 \mathrm{~kg})$. The animals were anesthetized with $100 \%$ oxygen (oxygen flow $200 \mathrm{ml} / \mathrm{kg} / \mathrm{min}$ ) and sevoflurane (Sevoflo ${ }^{\circledR}$ Abbott Laboratories Ltd, Kent, UK) using a face mask attached to a Bain circuit for the induction. Tracheal intubation with a 3.0 uncuffed tube was performed using a blind technique with the guidance of capnography [8] and the lungs were ventilated with an animal respirator (SN-480-5, Shinano Co., Ueda City, Japan). Ventilation was controlled to maintain end-tidal carbon dioxide ranging from 30-35 $\mathrm{mmHg}$, as measured by an $\mathrm{ETCO}_{2} / \mathrm{SpO}_{2}$ monitor $\left(\mathrm{CO}_{2} \mathrm{SMO}^{\circledR}\right.$, Novametrix Co., Wakefield, OH, USA), with a tidal volume of $25 \mathrm{ml} / \mathrm{kg}$, a respiratory rate of 30-35 breaths/min and inspiration time : expiration time (I : E) ratio of $1: 2$. To continuously monitor the end-tidal sevoflurane concentration between the intubation tube and the animal respirator, a gas analyzer (DatexOhmeda S/5 Anesthesia Monitor; GE Healthcare Finland, Helsinki, Finland) was used. The minimum alveolar concentration of sevoflurane was $3.7 \pm 0.16 \%$ in rabbits; therefore, the endtidal concentration of sevoflurane for maintenance of adequate anesthesia was controlled at 4\% [9]. A common carotid artery was cannulated for monitoring arterial blood pressure and intermittent analysis of arterial blood gases. A four-limb electrocardiogram was used for heart rate monitoring.

The rabbits were randomly assigned to four groups (control group [n =7], 2-mg group [n =7], 4-mg group [n=7], and 8 -mg group $[\mathrm{n}=7])$. The position of all animals was supine. The right ear vein was cannulated for intravenous (IV) fluid and drug administration. In the control group, normal saline $5 \mathrm{ml} / \mathrm{kg}$ was infused for 20 minutes using a syringe pump 1 hour before the study. In the study groups (2-mg, 4-mg and 8-mg groups), $50 \% \mathrm{MgSO}_{4}(50 \mathrm{mg} / \mathrm{ml}) 150-200 \mathrm{mg} / \mathrm{kg}$, which was diluted 10 times with normal saline, was infused using the same method as in the control group, and the maintenance dose of $\mathrm{MgSO}_{4} 25$ $\mathrm{mg} / \mathrm{kg} / \mathrm{h}$ was continuously infused to maintain a constant serum magnesium concentration (2.0-3.5 mmol/L). Drug dosages were determined by the weight of the rabbit. The serum magnesium concentrations were measured before administration of $\mathrm{MgSO}_{4}$ and just before and after the study by sampling from the carotid artery. Arterial blood gas analysis was performed using a GEMSTAT $^{\circledR}$ gas analyzer (Mallinckrodt Co., St. Louis, MO, USA). The rectal temperature of the rabbits was maintained at $38^{\circ} \mathrm{C}$ using a thermostat (Blanketrol II, 222, Cincinnati Sub-Zero Co., Cincinnati, OH, USA) and a heat lamp.

The right hind leg was shaved, and a longitudinal incision was made along the anterior leg. Dissection was performed to expose the right tibialis anterior muscle and common peroneal nerve. The common peroneal nerve was stimulated supramaximally at the posterolateral aspect of the knee with a $0.2-\mathrm{ms}$ square-wave stimulus from a peripheral nerve stimulator (DualStim $^{\circledR}$, Life-Tech Inc, Stafford, USA). TOF stimulation was applied once every $10 \mathrm{~s}$. The tendon of the tibialis anterior was attached to a force displacement transducer $\left(45196 A^{\circledR}\right.$, San-ei Co., Tokyo, Japan) with the use of 2.0 silk. The twitch response was quantified mechanomyographically with a preload tension (20 g). The mechanomyogram was recorded on a multichannel recorder (Biophysiograph $7748^{\circledR}$, San-ei Co., Tokyo, Japan). NMB was quantified by the first twitch (T1) of the TOF and TOF ratio (T4/T1).

After a stable recording of neuromuscular transmission had been established for $20 \mathrm{~min}$, rabbits in all groups received rocuronium $0.6 \mathrm{mg} / \mathrm{kg}$. After the complete depression of twitch on TOF, PTC was measured every 6 min. When PTC 1-2 appeared, sugammadex $4 \mathrm{mg} / \mathrm{kg}$ was administered as reversal agent in the control group and the 4-mg group, $2 \mathrm{mg} / \mathrm{kg}$ in the 2-mg group and $8 \mathrm{mg} / \mathrm{kg}$ in the 8 -mg group. The twitch recordings were evaluated for the following variables: time from the end of the injection of rocuronium to maximal twitch suppression (onset); time from the end of the injection of rocuronium to the appearance of PTC 1-2; time from the end of injection of rocuronium 
to recovery of T1 in the TOF to a value of $25 \%, 75 \%$, and $95 \%$ of control twitch tension (T1 $[25,75,95])$; time from the end of the injection of rocuronium to a TOF ratio of $90 \%$ (TOF [90]). At the end of the study, animals were given a lethal dose of pentobarbital and potassium chloride by IV injection.

\section{Statistical analysis}

Statistical analyses were conducted using SPSS 17.0 for window (SPSS Inc., Chicago, IL, USA). To determine the sample size, the technique used in a report was employed [10]. The mean onset of rocuronioum was $0.5 \pm 0.1$ min in rabbits. A minimum detected difference of $20 \%$ was considered significant. A sample size of 7 in each group was calculated to be appropriate to achieve a power of 0.8 and an a value of 0.05 . Oneway analysis of variance with post hoc Bonferroni correction was performed for multiple comparisons among groups. Differences were considered statistically significant at $\mathrm{P}<0.05$. All variables were expressed as mean \pm SD.

\section{Results}

\section{Serum magnesium concentrations}

Serum magnesium concentrations just before the study were
$0.60 \pm 0.12 \mathrm{mmol} / \mathrm{L}$ in the control group, $0.52 \pm 0.05 \mathrm{mmol} / \mathrm{L}$ in the 2 -mg group, $0.57 \pm 0.07 \mathrm{mmol} / \mathrm{L}$ in the 4 - $\mathrm{mg}$ group, and $0.54 \pm 0.07 \mathrm{mmol} / \mathrm{L}$ in the $8-\mathrm{mg}$ group $(\mathrm{P}=0.302)$. After the loading dose injection $\left(\mathrm{MgSO}_{4} 150-200 \mathrm{mg} / \mathrm{kg}\right)$, serum magnesium concentrations were $2.73 \pm 0.53 \mathrm{mmol} / \mathrm{L}$ in the $2-\mathrm{mg}$ group, $2.98 \pm 0.58 \mathrm{mmol} / \mathrm{L}$ in the $4-\mathrm{mg}$ group, and $3.03 \pm 0.26$ $\mathrm{mmol} / \mathrm{L}$ in the 8 -mg group $(\mathrm{P}=0.468)$. Just after the study, serum magnesium concentrations were $0.53 \pm 0.10 \mathrm{mmol} / \mathrm{L}$ in the control group, $2.12 \pm 0.23 \mathrm{mmol} / \mathrm{L}$ in the $2-\mathrm{mg}$ group, $2.11 \pm$ $0.18 \mathrm{mmol} / \mathrm{L}$ in the $4-\mathrm{mg}$ group, and $2.13 \pm 0.24 \mathrm{mmol} / \mathrm{L}$ in the 8-mg group $(\mathrm{P}<0.001)$. Total doses of $\mathrm{MgSO}_{4}$ were $590 \pm 97 \mathrm{mg}$ in the 2-mg group, $655 \pm 60 \mathrm{mg}$ in the 4-mg group, and $653 \pm$ $69 \mathrm{mg}$ in the $8-\mathrm{mg}$ group $(\mathrm{P}=0.226)$. There were no differences in serum magnesium concentration and total dose between the study groups (Table 1).

\section{Onset time of rocuronium injection and time for appearance of PTC 1-2}

The onset time of rocuronium in the study groups (2-mg group [0.43 $\pm 0.06 \mathrm{~min}], 4-\mathrm{mg}$ group $[0.42 \pm 0.04 \mathrm{~min}]$ and 8 -mg group $[0.43 \pm 0.04 \mathrm{~min}])$ was significantly shortened than that in the control group $[0.63 \pm 0.1 \mathrm{~min}](\mathrm{P}<0.001)$. The time for appearance of PTC $1-2$ in the study groups (2-mg group [30.0 $\pm 6.9 \mathrm{~min}], 4$-mg group [26.4 $\pm 5.8 \mathrm{~min}]$ and $8-\mathrm{mg}$ group [28.2 \pm

Table 1. Serum Magnesium Concentration (mmol/L) and Total Dose (mg) during $\mathrm{MgSO}_{4}$ Infusion (150-200 mg/kg Bolus and $25 \mathrm{mg} / \mathrm{kg} / \mathrm{h}$ Continuously) in Rabbits

\begin{tabular}{|c|c|c|c|c|}
\hline & Before $\mathrm{MgSO}_{4}$ & After $\mathrm{MgSO}_{4}$ bolus & Just after study & Total dose of $\mathrm{MgSO}_{4}$ \\
\hline Control $(\mathrm{n}=7)$ & $0.60 \pm 0.12$ & & $0.53 \pm 0.10$ & \\
\hline Group 2-mg $(\mathrm{n}=7)$ & $0.52 \pm 0.05$ & $2.73 \pm 0.53$ & $2.12 \pm 0.23^{*}$ & $590 \pm 97$ \\
\hline Group 4-mg $(\mathrm{n}=7)$ & $0.57 \pm 0.07$ & $2.98 \pm 0.58$ & $2.11 \pm 0.18^{*}$ & $655 \pm 60$ \\
\hline Group 8-mg $(\mathrm{n}=7)$ & $0.54 \pm 0.07$ & $3.03 \pm 0.26$ & $2.13 \pm 0.24^{*}$ & $653 \pm 69$ \\
\hline$P$ value & 0.302 & 0.468 & $<0.001$ & 0.226 \\
\hline
\end{tabular}

Data are expressed as mean \pm SD. Control: sugammadex $4 \mathrm{mg} / \mathrm{kg}$, Group 2-mg: sugammadex $2 \mathrm{mg} / \mathrm{kg}$, Group 4-mg: sugammadex $4 \mathrm{mg} / \mathrm{kg}$, Group 8-mg: sugammadex $8 \mathrm{mg} / \mathrm{kg}$. ${ }^{*} \mathrm{P}<0.001$ compared with Control group. No differences were detected among the study groups.

Table 2. Onset and Recovery Times (min) of Rabbits Given Rocuronium $0.6 \mathrm{mg} / \mathrm{kg}$ after Reversal of Sugammadex during $\mathrm{MgSO}_{4} \mathrm{Infusion}_{(150-200}$ $\mathrm{mg} / \mathrm{kg}$ bolus and $25 \mathrm{mg} / \mathrm{kg} / \mathrm{h}$ Continuously)

\begin{tabular}{lccccc}
\hline & Onset & PTC 1-2 & T1 [75] & T1 [95] & TOF [90] \\
\hline Control $(\mathrm{n}=7)$ & $0.63 \pm 0.10$ & $14.4 \pm 4.2$ & $1.44 \pm 0.69^{\dagger}$ & $2.73 \pm 1.23^{\dagger}$ & $1.31 \pm 0.57^{\dagger}$ \\
Group 2-mg $(\mathrm{n}=7)$ & $0.43 \pm 0.06^{*}$ & $30 \pm 6.9^{*}$ & $2.24 \pm 0.45$ & $3.93 \pm 0.93$ & $2.03 \pm 0.47$ \\
Group 4-mg $(\mathrm{n}=7)$ & $0.42 \pm 0.04^{*}$ & $26.4 \pm 5.8^{*}$ & $1.43 \pm 0.49^{\dagger}$ & $2.53 \pm 0.78^{\dagger}$ & $1.24 \pm 0.30^{\dagger}$ \\
Group 8-mg $(\mathrm{n}=7)$ & $0.43 \pm 0.04^{*}$ & $28.2 \pm 7.5^{*}$ & $1.14 \pm 0.58^{\dagger}$ & $2.44 \pm 0.73^{\dagger}$ & $1.14 \pm 0.40^{\dagger}$ \\
P value & $<0.001$ & $<0.001$ & $<0.001$ & $<0.001$ & $<0.001$
\end{tabular}

Data are expressed as mean \pm SD. Control: sugammadex $4 \mathrm{mg} / \mathrm{kg}$, Group 2-mg: sugammadex $2 \mathrm{mg} / \mathrm{kg}$, Group 4-mg: sugammadex $4 \mathrm{mg} / \mathrm{kg}$, Group 8-mg: sugammadex $8 \mathrm{mg} / \mathrm{kg}$. Onset: the time from injection of rocuronium to $100 \%$ twitch depression, PTC $1-2$ : the time from injection of rocuronium to $1-2$ twitches of post-tetanic count (PTC), T1 [75], T1 [95]: the time from injection of sugammadex to $75 \%$ and $95 \%$ recovery of first twitch of train-of-four (TOF), respectively, TOF[90]: the time from injection of sugammadex to TOF ratio (T4/T1) of $90 \%$. ${ }^{*} \mathrm{P}<0.001$ compared with Control group. ${ }^{\dagger} \mathrm{P}<0.001$ compared with Group 2 -mg. 


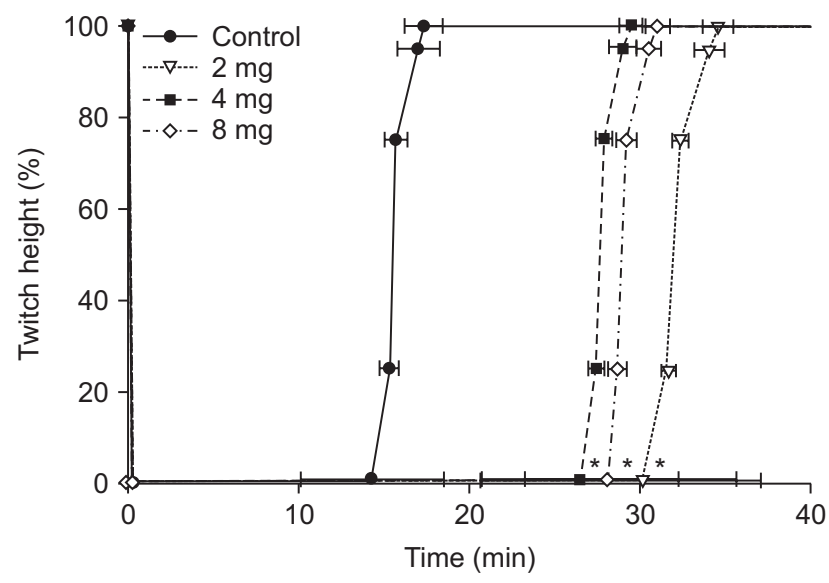

Fig. 1. The time ( $\mathrm{min}$ ) for appearance of post-tetanic count 1-2 given rocuronium $0.6 \mathrm{mg} / \mathrm{kg}$ during $\mathrm{MgSO}_{4}$ infusion $(150-200 \mathrm{mg} / \mathrm{kg}$ bolus and $25 \mathrm{mg} / \mathrm{kg} / \mathrm{h}$ continuously) in rabbits. Individual points represent mean twitch height (\% control). Data are mean \pm SD. ${ }^{*} \mathrm{P}<0.001$ compared with the control group.

$7.5 \mathrm{~min}])$ was significantly prolonged than in the control group [14.4 $\pm 4.2 \mathrm{~min}](\mathrm{P}<0.001$; Fig. 1, Table 2).

\section{Recovery time from the end of sugammadex injection}

TOF [90] in the $2-\mathrm{mg}$ group $(2.03 \pm 0.47 \mathrm{~min})$ was significantly longer than in the other groups $(1.31 \pm 0.57 \mathrm{~min}$ in the control group, $1.24 \pm 0.30 \mathrm{~min}$ in the 4 -mg group, and $1.14 \pm 0.40$ min in the 8-mg group, $\mathrm{P}<0.001$; Table 2). T1 [75] in the 2-mg group ( $2.24 \pm 0.45 \mathrm{~min}$ ) was longer than in the other groups (1.44 $\pm 0.69 \mathrm{~min}$ in the control group, $1.43 \pm 0.49 \mathrm{~min}$ in the $4-\mathrm{mg}$ group, and $1.14 \pm 0.58 \mathrm{~min}$ in the $8-\mathrm{mg}$ group, $\mathrm{P}<0.001)$. T1 [95] in the 2-mg group ( $3.93 \pm 0.93 \mathrm{~min})$ was longer than in the other groups $(2.73 \pm 1.23 \mathrm{~min}$ in the control group, $2.53 \pm 0.78$ $\mathrm{min}$ in the 4-mg group, and $2.44 \pm 0.73 \mathrm{~min}$ in the 8 -mg group, $\mathrm{P}<0.001$; Fig. 2, Table 2).

The hemodynamic data and $\mathrm{ETCO}_{2}$ were not different between all groups, and did not affect the results. These results were not displayed.

\section{Discussion}

In this study, more than $590 \mathrm{mg}$ of $\mathrm{MgSO}_{4}$ was required to maintain a serum magnesium concentration above $2.0 \mathrm{mmol} / \mathrm{L}$. The onset time of rocuronium in the study groups was significantly shorter than in the control group and the time for appearance of PTC 1-2 in the study groups was significantly longer than in the control group. In addition, TOF [90], T1 [75] and T1 [95] from the end of sugammadex injection in the 2-mg group were significantly extended relative to those in the other groups.

The normal range of serum magnesium concentration is $0.7-$

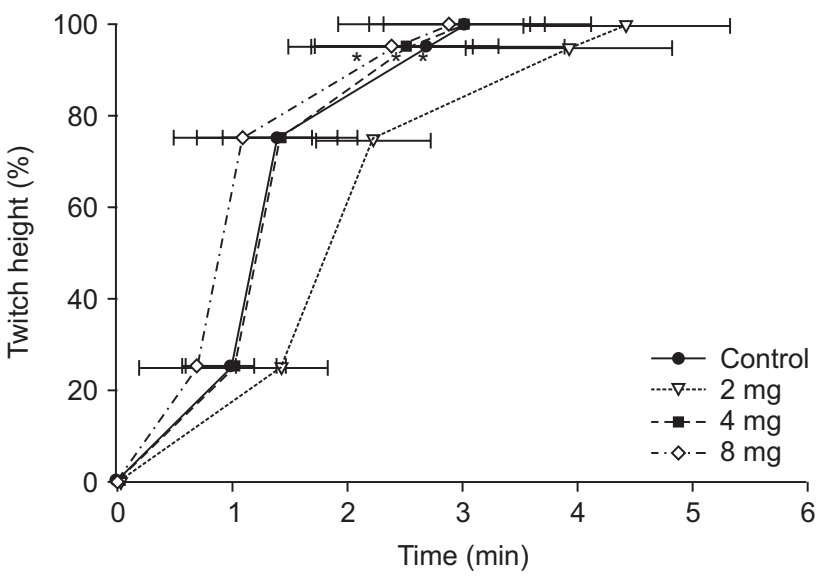

Fig. 2. The recovery time ( $\mathrm{min}$ ) after each dose of sugammadex at post-tetanic count 1-2 from the relaxation given rocuronium $0.6 \mathrm{mg} /$ $\mathrm{kg}$ during $\mathrm{MgSO}_{4}$ infusion (150-200 mg/kg bolus and $25 \mathrm{mg} / \mathrm{kg} / \mathrm{h}$ continuously) in rabbits. Individual points represent mean twitch height (\% control). Data are mean $\pm \mathrm{SD} .{ }^{*} \mathrm{P}<0.001$ compared with the 2 -mg group.

$0.9 \mathrm{mmol} / \mathrm{L}$ in humans [11] and $0.5-0.8 \mathrm{mmol} / \mathrm{L}$ in rabbits [12]. The serum magnesium concentration in this study was $0.52-0.60$ mmol/L. Previous studies [7,13-15] found interactions between muscle relaxants and $\mathrm{MgSO}_{4} 40-60 \mathrm{mg} / \mathrm{kg}$, which was single IV bolus administered. Therefore, these conditions were very different from eclampsia treatment, which requires a sustained serum magnesium concentration $(2.0-3.5 \mathrm{mmol} / \mathrm{L})$ with a continuous infusion of $\mathrm{MgSO}_{4}$. Even in the study with humans, serum magnesium concentrations were not maintained at the level necessary to treat eclampsia [16]. In the current study, the loading dose of $\mathrm{MgSO}_{4} 150-200 \mathrm{mg} / \mathrm{kg}$ was administered for 20 min using a syringe pump before study, and a maintenance dose of $\mathrm{MgSO}_{4} 25 \mathrm{mg} / \mathrm{kg} / \mathrm{h}$ was continuously administered to resemble the clinical situation of eclampsia treatment, maintaining a constant serum magnesium concentration of $2.0-3.5 \mathrm{mmol} / \mathrm{L}$. Therefore, the effect of serum magnesium at the therapeutic concentration for eclampsia on the reversal of sugammadex could be evaluated.

An increase in serum magnesium concentration can induce hypotension. It is the results which magnesium directly antagonizes the calcium effect and acts to vascular smooth muscle and induces vasodilation. Indirectly, magnesium induces a sympathetic block and decreases vasomotor reflex and blood retention of peripheral veins, due to skeletal muscle relaxation. Finally, magnesium decreases venous return to the left ventricle and cardiac output [17]. However, in this study, there were no differences in blood pressure or heart rate between groups, regardless of sugammadex administration. The reason for this finding was not clear, but might be associated with the greater hemodynamic effect of an inhalational anesthetic agent other than magnesium.

In rabbits, the effective dose resulting in a $50 \%$ reduction of 
twitch tension $\left(\mathrm{ED}_{50}\right)$ and the effective dose resulting in a $95 \%$ reduction of twitch tension $\left(\mathrm{ED}_{95}\right)$ are $61.5 \pm 5.3 \mu \mathrm{g} / \mathrm{kg}$ and 95.1 $\pm 6.7 \mu \mathrm{g} / \mathrm{kg}$, respectively [18]. Kim et al. [19] reported that the $\mathrm{ED}_{50}$ value of rocuronium for rabbits was $56.5 \mathrm{mg} / \mathrm{kg}$, a level that was $40 \%$ of the level reported for humans [20]. Therefore, the dose of rocuronium was $0.6 \mathrm{mg} / \mathrm{kg}$ was used for a deep $\mathrm{NMB}$, which is the same dose used for intubation in humans. $\mathrm{MgSO}_{4}$ administered $15 \mathrm{~min}$ before propofol anesthesia reduces the onset time of rocuronium by approximately $35 \%$ and prolongs the total recovery time by approximately $25 \%$ [7]. In the current study, the onset time of rocuronium $0.6 \mathrm{mg} / \mathrm{kg}$ in the study groups was significantly shorter than in the control group. This decrease in onset time might be associated with serum magnesium concentrations above $2.0 \mathrm{mmol} / \mathrm{L}$. The onset time of rocuronium $0.6 \mathrm{mg} / \mathrm{kg}$ in humans is approximately $1.5 \mathrm{~min}$ [21]. The decreased onset time in rabbits might be due to the increased dose $\left(7 \times \mathrm{ED}_{95}\right)$ used in rabbits compared with the human dose $\left(2 \times \mathrm{ED}_{95}\right)$. The longer time $(26-30 \mathrm{~min})$ for the appearance of PTC 1-2 in the study groups compared to the control group (14 min) also might be associated with serum magnesium concentration levels. Clinically, the presence or absence of $\mathrm{MgSO}_{4}$ may have an effect on the emergent reversal with sugammadex after muscle relaxant.

The recommended dose of sugammadex is $2 \mathrm{mg} / \mathrm{kg}$ for a moderate NMB, which is determined by a TOF count above 2 twitches, $4 \mathrm{mg} / \mathrm{kg}$ for a deep NMB, which is determined by a PTC below 10, and $16 \mathrm{mg} / \mathrm{kg}$ for emergent reversal immediately after NMBA administration [22]. In this study, the dose of sugammadex for reversal was $4 \mathrm{mg} / \mathrm{kg}$, because PTC was $1-2$ when sugammadex was administered. In addition, $2 \mathrm{mg} / \mathrm{kg}$ and $8 \mathrm{mg} / \mathrm{kg}$ of sugammadex were used to evaluate the efficiency of reversal with $\mathrm{MgSO}_{4}$ pretreatment.

Sugammadex could reverse a rocuronium-induced NMB in a dose-response manner, even among patients treated with $\mathrm{MgSO}_{4}$ [23]. Clinically, there was no effect of $\mathrm{MgSO}_{4}$ pretreatment on the sugammadex reversal for deep NMB with rocuronium [7]. In this study, $\mathrm{T} 1$ [95] in the control and the 4-mg group, which received identical doses of sugammadex, did not vary. These results meant that the pretreatment $\mathrm{MgSO}_{4}$ did not affect the reversal of sugammadex under the constant serum magnesium concentration of $2.0-3.5 \mathrm{mmol} / \mathrm{L}$ in rabbits. In contrast, there was no difference in T1 [95] between the 4-mg group and the 8-mg group. This might be the result of a ceiling effect of sugammadex, although further study is needed. The prolongation of T1 [95] (3.93 $\pm 0.93 \mathrm{~min})$ in the 2-mg group might be due to a dose of not a deep NMB but a moderate NMB.

TOF ratio represents a presynaptic receptor block, whereas a post-synaptic receptor block is expressed by a depression in the single twitch response [24]. In the presence of appropriate concentrations of sugammadex, only a low concentration of free NMBA remains in the neuromuscular junction and will preferentially block post-synaptic acetylcholine receptors. This could explain why, after an optimal dose of sugammadex, the recovery of the TOF ratio to 0.9 precedes the recovery of $\mathrm{T} 1$, and why the TOF ratio may be fully recovered when this is not yet the case for T1 [25]. When antagonizing with classical reversal agents (anticholinesterase drugs) or natural recovery, the time course of recovery from NMBA varies from the case with sugammadex; first, there is the full return of T1 and then recovery of the TOF ratio to $90 \%[10,26]$. In this study, TOF [90] appeared at a time similar to T1 [75], and T1 [95] appeared later than TOF [90]. This might be due to the reversal nature of sugammadex.

One limitation of this study was that anesthetic maintenance was performed with sevoflurane. Inhalational anesthesia is more commonly used in clinical practice than intravenous anesthesia, so we used an inhalational anesthetic agent for anesthesia maintenance. However, although it remains equivocal [27,28], the effect of sevoflurane on the recovery of a neuromuscular blockade by rocuronium cannot be completely ignored. In addition, one report suggested that sugammadex could not be affected by inhalational agents [29]. Therefore, the effect of sevoflurane might be limited. Another limitation was that we tested only a small number ( $\mathrm{n}=7$ in each condition) of rabbits in order to minimize sacrifice of the animals, based on Min et al. [10]. If the number of rabbits was increased after a measurement of sample size, significant results may be obtained. Although eclampsia occurs only in women, male animals have undergone in this animal study due to disturbances such as the menstrual cycle.

In conclusion, the reversal of sugammadex from a deep rocuronium-induced NMB during the constant serum magnesium concentration of $2.0-3.5 \mathrm{mmol} / \mathrm{L}$ was not affected in rabbits. However, the reversal effect of sugammadex varied depending on the dose.

\section{References}

1. Duley L. The global impact of pre-eclampsia and eclampsia. Semin Perinatol 2009; 33: 130-7.

2. Sibai BM. Magnesium sulfate prophylaxis in preeclampsia: evidence from randomized trials. Clin Obstet Gynecol 2005; 48: 478-88.

3. Lee C, Zhang X, Kwan WF. Electromyographic and mechanomyographic characteristics of neuromuscular block by magnesium sulphate in the pig. Br J Anaesth 1996; 76: 278-83. 
4. Jones RK, Caldwell JE, Brull SJ, Soto RG. Reversal of profound rocuronium-induced blockade with sugammadex: a randomized comparison with neostigmine. Anesthesiology 2008; 109: 816-24.

5. Kim MH, Lee KY, Lee KY, Min BS, Yoo YC. Maintaining optimal surgical conditions with low insufflation pressures is possible with deep neuromuscular blockade during laparoscopic colorectal surgery: a prospective, randomized, double-blind, parallel-group clinical trial. Medicine (Baltimore) 2016; 95: e2920.

6. Kim HJ, Lee K, Park WK, Lee BR, Joo HM, Koh YW, et al. Deep neuromuscular block improves the surgical conditions for laryngeal microsurgery. Br J Anaesth 2015; 115: 867-72.

7. Czarnetzki C, Tassonyi E, Lysakowski C, Elia N, Tramèr MR. Efficacy of sugammadex for the reversal of moderate and deep rocuroniuminduced neuromuscular block in patients pretreated with intravenous magnesium: a randomized controlled trial. Anesthesiology 2014; 121: 59-67.

8. Flecknell P. Laboratory animal anaesthesia. 4th ed. New York, Elsevier. 2016, pp 33-7.

9. Scheller MS, Saidman LJ, Partridge BL. MAC of sevoflurane in humans and the New Zealand white rabbit. Can J Anaesth 1988; 35 : 153-6.

10. Min HK, Kim KS, Lee GS. Rocuronium-induced neuromuscular block after long pretreatment of magnesium sulfate in rabbits. Korean J Anesthesiol 2007; 52: 443-8.

11. Musso CG. Magnesium metabolism in health and disease. Int Urol Nephrol 2009; 41: 357-62.

12. Barlet JP. Plasma calcium, inorganic phosphorus and magnesium levels in pregnant and lactating rabbits. Reprod Nutr Dev 1980; 20: 64751.

13. Fuchs-Buder T, Wilder-Smith OH, Borgeat A, Tassonyi E. Interaction of magnesium sulphate with vecuronium-induced neuromuscular block. Br J Anaesth 1995; 74: 405-9.

14. Lampl E, Dandoy M. Priming of atacurium with magnesium. Br J Anaesth 1993; 70: 72.

15. James MF, Schenk PA, van der Veen BW. Priming of pancuronium with magnesium. Br J Anaesth 1991; 66: 247-9.

16. Groudine SB, Soto R, Lien C, Drover D, Roberts K. A randomized, dose-finding, phase II study of the selective relaxant binding drug, Sugammadex, capable of safely reversing profound rocuronium-induced neuromuscular block. Anesth Analg 2007; 104: 555-62.

17. Mordes JP, Wacker WE. Excess magnesium. Pharmacol Rev 1977; 29: 273-300.

18. Min HK, Kim KS, Lee GS. Neuromuscular interactions between mivacurium and rocuronium in rabbits. Korean J Anesthesiol 1998; 34 : 686-93.

19. Kim KS, Shim JC, Jun JH, Lee KH, Chung CW. Rabbits treated with chronic isepamicin are resistant to mivacurium and rocuronium. Anesth Analg 1999; 88: 654-8.

20. Diefenbach C, Nigrovic V, Mellinghoff H, Buzello W. Muscle relaxants. New substances and neuromuscular monitoring. Anaesthesist 1997; 46: 3-13.

21. Foldes FF, Nagashima H, Nguyen HD, Schiller WS, Mason MM, Ohta Y. The neuromuscular effects of ORG9426 in patients receiving balanced anesthesia. Anesthesiology 1991; 75: 191-6.

22. Kopman AF. Sugammadex: a revolutionary approach to neuromuscular antagonism. Anesthesiology 2006; 104: 631-3.

23. Sakurai Y, Uchida M, Aiba J, Mimura F, Yamaguchi M, Kakumoto M. Reversal of rocuronium-induced neuromuscular blockade with sugammadex in patients for cesarean delivery treated with magnesium sulfate. Masui 2014; 63: 315-9.

24. Bowman WC. Prejunctional and postjunctional cholinoceptors at the neuromuscular junction. Anesth Analg 1980; 59: 935-43.

25. Staals LM, Driessen JJ, Van Egmond J, De Boer HD, Klimek M, Flockton EA, et al. Train-of-four ratio recovery often precedes twitch recovery when neuromuscular block is reversed by sugammadex. Acta Anaesthesiol Scand 2011; 55: 700-7.

26. Kim KS, Jeon JW, Koh MS, Shim JH, Cho SY, Suh JK. The duration of immobilization causes the changing pharmacodynamics of mivacurium and rocuronium in rabbits. Anesth Analg 2003; 96: 438-42.

27. Lowry DW, Mirakhur RK, McCarthy GJ, Carroll MT, McCourt KC. Neuromuscular effects of rocuronium during sevoflurane, isoflurane, and intravenous anesthesia. Anesth Analg 1998; 87: 936-40.

28. Maidatsi PG, Zaralidou AT, Gorgias NK, Amaniti EN, Karakoulas KA, Giala MM. Rocuronium duration of action under sevoflurane, desflurane or propofol anaesthesia. Eur J Anaesthesiol 2004; 21: 781-6.

29. Vanacker BF, Vermeyen KM, Struys MM, Rietbergen H, Vandermeersch E, Saldien V, et al. Reversal of rocuronium-induced neuromuscular block with the novel drug sugammadex is equally effective under maintenance anesthesia with propofol or sevoflurane. Anesth Analg 2007; 104: $563-8$ 